\title{
APHIS to Collaborate with HSUS on Disaster Preparedness
}

On 22 May, the U.S. Department of Agriculture (USDA) Animal and Plant Health Inspection Service (APHIS) announced the signing of a Memorandum of Understanding ${ }^{1}$ with the Humane Society of the United States (HSUS), the nation's largest animal protection organization. APHIS and HSUS agree to coordinate disaster preparedness and response efforts involving animals by exchanging information during disasters and collaborating on disaster planning exercises, operational procedures, equipment, and training. These organizations expect their agreement to promote standards for animal preparedness to the public, businesses, disaster organizations, and emergency managers.

Currently, HSUS has formal agreements with The American Red Cross and the Federal Emergency Management Agency (FEMA) for disaster response coordination and preparedness education. Additional information about HSUS disaster preparedness and response guidelines is available on the HSUS website (http:// www.hsus.org/disaster).

Earlier this year, the Laboratory Animal Management Association (LAMA), with support of the Office of Laboratory Animal Welfare (OLAW), launched a website (http://www.lama-online.org/ OLAW-1.html) dedicated to disaster planning and management, based on an educational seminar it conducted in May 2002. This site contains presentations and information discussed at that meeting and links to relevant federal and nonfederal resources on disaster management. The NIH Disaster Response website (http:// oacu.od.nih.gov/disaster/index. $\mathrm{htm}$ ) is another useful resource for disaster management.

\section{Regulation Updates}

European Commission Drafts New Chemicals Legislation for Consultation On 7 May, in a development likely to increase the number of animals tested to evaluate safety of chemicals, the European Commission published draft legislation that would "overhaul and modernize the EU's regulatory system for chemicals2." The proposed system, which will be called "REACH" (for Registration, Evaluation, and Authorization of Chemicals), will replace 40 different existing regulations. This new legislation is intended to "increase the protection of human health and the environment from exposure to chemicals while at the same time to maintain and enhance the competitiveness and innovative capability of the EU chemicals industry2."

To minimize the need for animal testing, as well as to keep costs down, the proposal includes a system of data sharing among companies and increased flexibility of testing requirements. Non-confidential data generated by REACH will be made available through a publicly accessible database.

The Commission expects that it may take up to 11 years to phase in the system, which will include tighter controls for chemicals of highest concern (e.g., carcinogens, mutagens and reproductive toxicants). The Commission expects that $~ 80 \%$ of all substances will only have to be registered, while the rest will require safety testing and subsequent authorization.

FDA to Simplify Regulations for Liquid and Free-Choice Medicated Feed On 28 May, the Food and Drug Administration (FDA) proposed to change the regulations for liquid medicated feed and free-choice medicated feed. In doing so, it hopes to clarify the following points: "What data are required to demonstrate chemical and physical stability of a drug in liquid feed; how such data may be submitted for use in the new animal drug approval process; and which liquid medicated feeds may be manufactured in a feed manufacturing facility that has not obtained a medicated feed mill license from FDA ${ }^{3}$." The FDA is proposing to exempt from the feed mill license requirement facilities manufacturing liquid feeds containing a Category I drug with a published formula and/or specifications. The FDA wants to ensure that regulations for free-choice medicated feed are "consistent with the requirements for liquid medicated feed, and that provisions for free-choice medicated feed and liquid medicated feed comply with the terms of the Animal Drug Availability Act (ADAA) of 1996 (ref. 3)."

\section{References}

1. USDA APHIS. Press release. USDA signs memorandum of understanding with the Humane Society of the United States. (22 May 2003). http://www.aphis.usda.gov/ Ipa/news/2003/05/adpmemo_ac.html.

2. European Commission. Press release. Commission publishes draft new Chemicals Legislation for consultation. (7 May 2003). http://europa.eu.int/rapid/ start/cgi/guesten.ksh?p_action.gettxt= gt\&doc $=|P / 03 / 646| 0 \mid$ RAPID\&Ig=EN\& display=

3. FDA. Proposed rule. Requirements for liquid medicated animal feed and free-choice medicated animal feed. Federal Register 68, 31645-31652 (28 May 2003). http:// www.fda.gov/OHRMS/DOCKETS/98fr/03 $-12974 . \mathrm{html}$ 